\section{Case Reports in Neurology}

Case Rep Neurol 2021;13:251-258

DOI: $10.1159 / 000513302$

Published online: April 26, 2021
(C) 2021 The Author(s)

Published by S. Kar OPEN

www.karger.com/crn

This article is licensed under the Creative Commons Attribution-NonCommercial 4.0 International License (CC BY-NC) (http://www.karger.com/Services/OpenAccessLicense).

Usage and distribution for commercial purposes requires written permission.

\title{
Intentional Supernumerary Motor Phantom Limb after Right Cerebral Stroke: A Case Report
}

\author{
Mai Yamada ${ }^{a}$ Yoshimi Sasahara $^{a}$ Makiko Seto $^{b}$ Akira Satoh $^{b}$ \\ Mitsuhiro Tsujihata ${ }^{b}$ \\ aSection of Rehabilitation, Nagasaki Kita Hospital, Nagasaki, Japan; bSection of \\ Neurology, Nagasaki Kita Hospital, Nagasaki, Japan
}

\section{Keywords}

Supernumerary phantom limb $\cdot$ Intentional motor phantom limb $\cdot$ Premotor cortex $\cdot$ Stroke

\begin{abstract}
A 47-year-old right-handed man was admitted to our hospital for rehabilitation after right basal ganglion hematoma. On day 57 , he noticed a supernumerary motor phantom limb (SPL) involving his right arm, originating at the level of the elbow. The most notable finding of his SPL was the motor characteristic. When the subject had the intention to move the upper paralyzed limb simultaneously with the trainer's facilitating action, he said "there is another arm." The intention to move the paralyzed arm alone or passive movement of the paralyzed arm did not induce the SPL. He showed a severe left sensorimotor impairment and mild hemineglect, but no neglect syndromes of the body (e.g., asomatognosia, somatoparaphrenia, personification and misoplegia, or anosognosia) were observed. Brain MRI demonstrated a hematoma in the right temporal lobe subcortex, subfrontal cortex, putamen, internal capsule, and thalamus. Single-photon emission computed tomography images showed more widespread hypoperfusion in the right hemisphere in comparison to the lesions on MRI. However, the premotor cortex was preserved. Our case is different from Staub's case in that SPL was not induced by the intention to move the paralyzed limb alone; rather, it was induced when the patient intended to move the paralyzed limb with a trainer's simultaneous facilitating action. The SPL may reflect that an abnormal closed-loop function of the thalamocortical system underlies the phantom phenomenon. However, despite the severe motor and sensory impairment, the
\end{abstract}

\begin{tabular}{ll}
\hline & Mitsuhiro Tsujihata \\
& Section of Neurology, Nagasaki Kita Hospital \\
& 800, Motomuragou, Togitsuchou, Nishisonogigun \\
Nagasaki, $851-2103$ (Japan) \\
kita_m_tsuji@mx22.tiki.ne.jp
\end{tabular}




\section{Case Reports in Neurology}

Case Rep Neurol 2021;13:251-258

DOI: $10.1159 / 000513302$

Yamada et al: Phantom Limb

afferent pathway from the periphery to the premotor cortex may have been partially preserved, and this may have been related to the induction of SPL.

(C) 2021 The Author(s)

Published by S. Karger AG, Basel

\section{Introduction}

The term "phantom limb" (PL) is used to denote a dissociation between the perceived position of an intact body part and its actual position, wherein a patient experiences a vivid illusion involving their paralyzed or amputated limbs. Although PL syndrome occurs in the vast majority of patients with limb amputations and is commonly found after avulsion or anesthetic block of the brachial plexus [1], the persisting belief in the existence of an additional limb after unilateral stroke is very unusual [2]. When the real limb is present, as in the case of stroke, this phenomenon is referred to as supernumerary PL (SPL) [3] or phantom third limb $[1,4]$. The PL phenomenon has been reported not only in amputees but also in patients with deafferentation from lesions at various levels of the neuraxis, including the peripheral nerves, plexus, spinal cord, posterior columns, subcortical regions, and cortical regions [1,5].

PLs resulting from cerebral lesions are considered to be rare [6-8]. Miyazawa et al. [8] reported that only 20 case reports on SPL resulting from stroke or hemorrhage have been published in the last 70 years. This phenomenon is thought to be more common among patients with right hemispheric damage [8] and has been associated with lesions of various structures, including the pons, internal capsule, corona radiata, basal ganglia, thalamus, medial frontal lobe, and cerebral hemispheres [6-8].

Staub et al. [9] reported the case of a patient who showed SPL only in association with motor intent directed at a hemiplegic-anesthetic upper limb, and Khateb et al. [10] reported the case of a patient with SPL who rarely showed intentionally triggered SPL, similar to Staub's case.

We herein report a case of SPL that was only evoked with motor intent directed to the paralytic-anesthetic upper limb.

\section{Case Presentation}

A 47-year-old right-handed man was admitted to our hospital for rehabilitation after right basal ganglia hematoma. On February 6, 2015, he noted left paralysis after bathing and was emergently transferred to a university hospital; hematoma removal surgery was performed under a diagnosis of cerebral hemorrhage. On day 55, he showed a complete left sensorimotor hemiplegia, and the left upper extremity, fingers, and lower extremity all were at Brunnström stage II. The degree of sensory impairment was graded on a 10-point scale. The superficial sensation, i.e., tactile sensation, was $3 / 10$ in the upper extremity and 4/10 in the lower extremity, and the pain and temperature sensation was $2 / 10$ in the upper extremity and 3/10 in the lower extremity. The deep sensation, i.e., vibratory sense, position sense, and kinesthetic senses, was $1 / 10$ in the upper extremity and 2/10 in the lower extremity. The patient complained of pain in the left shoulder and fingers; the level was judged to be $8 / 10$ using a visual analogue scale. He showed a mild left homonymous hemianopsia. The patient had no history of epilepsy, psychiatric illnesses, or drug or alcohol misuse.

\section{Karger'=}




\section{Case Reports in Neurology}

Case Rep Neurol 2021;13:251-258

DOI: $10.1159 / 000513302$

Yamada et al.: Phantom Limb

\section{Neuropsychological Assessments}

On day 55, the patient's Mini-Mental State Examination score was 29 out of 30, and his IQ was 80 on Kohs' Block Design Test. The patient's Wechsler Adult Intelligence Scale (WAIS-III) results were as follows: Full-scale IQ, 77; Verbal IQ, 100; Performance IQ, 57; Verbal Comprehension, 102; Perceptual Organization, 63; Working Memory, 94; and Processing Speed, 54. The results showed a slight decrease in Performance IQ. The Frontal Assessment Battery score was 18/20, a Trail Making Test was performed in $285 \mathrm{~s}$ in part $\mathrm{A}$, and $215 \mathrm{~s}$ in part B, and the patient's score in the Clinical Assessment for Attention was lower than the cut-off values. The results of these tests showed the presence of attention disturbance. In the Behavioural Inattention Test, the patient scored 122/146 in the conventional test, and 60/81 on the behavioral test. The patient's score on the Catherine Bergego Scale was 12/30, suggesting the presence of left hemineglect. No neglect syndromes of the body (e.g., asomatognosia, somatoparaphrenia, personification and misoplegia, or anosognosia) were observed.

\section{Supernumerary Phantom Limb}

On day 57, the patient reported noticing for the first time an SPL involving his left arm, originating at the level of the elbow during rehabilitation (Fig. 1). The most notable finding of the SPL was its motor characteristic. When the subject intended to move the upper limb on the paralyzed side while the trainer was simultaneously performing a facilitation operation in the direction of shoulder flexion, he pointed near the pectoralis major muscle and said: "I have another arm here." The intention to move the paralyzed arm at the same time as the trainer's facilitation operation was sufficient to trigger the illusion, whereas the SPL phenomenon was not induced by passive upper limb movement. Attempts to simply move the paralyzed arm did not cause the SPL phenomenon. The usual facilitation operation for paralyzed muscles in poststroke patients is performed 50 times per set for 2 sets. He noted the appearance of the PL after about 20 facilitation operations.

He sensed that the SPL was not his own hand and felt strange, but he reported being sure that the SPL would be easier to move if it overlapped with the real arm. The patient said that, visually, the third limb protruded below the forearm from inside the paralyzed limb, and that it was transparent like water, with only the outline visible.

The patient tried to draw the PL, but he was unable to do so due to constructional apraxia. A staff member drew the PL according to his explanation. With the exception of mild left hemineglect, his SPL was not associated with anosognosia, asomatognosia, or somatoparaphrenia. The frequency of the SPL phenomenon induced by facilitation operations gradually decreased and disappeared on day 90 . No body illusion was found for other parts of the body.

\section{Imaging Findings}

On day 28, brain magnetic resonance imaging (MRI) demonstrated a hematoma of irregular shape with a maximum diameter of $9 \mathrm{~cm}$ in the right temporal lobe subcortex, subfrontal cortex, putamen, internal capsule, and thalamus (Fig. 2a). The easy Z-score imaging system and voxel-based stereotaxic extraction estimation analyses of the single-photon emission computed tomography images displayed more widespread hypoperfusion in the right hemisphere than had been noted on MRI (Fig. 2b). The lesion sites where the extent $\%$ was $>80 \%$ in the voxel-based stereotaxic extraction estimation analysis were as follows: frontal lobe (inferior frontal gyrus [g.]), parietal lobe (angular g., supramarginal g., and inferior parietal lobule), temporal lobe (superior, middle and inferior temporal, as well as transverse temporal g.), occipital lobe (superior, middle and inferior occipital g.), insula, and basal ganglia

\section{Karger'=}




\section{Case Reports in Neurology}

Case Rep Neurol 2021;13:251-258

DOI: $10.1159 / 000513302$

Yamada et al.: Phantom Limb

(putamen, globus pallidus, and caudate), Brodmann area 37. The thalamus showed $70 \%$ as a whole; however, the lateral posterior nucleus, ventral anterior nucleus, ventral lateral nucleus, ventral posterior lateral nucleus, ventral posterior medial nucleus, and subthalamic nucleus showed a $100 \%$ decrease.

\section{Discussion}

The presence of a PL resulting from a cerebral lesion has been reported to be a rare event. Antoniello et al. [11] systematically investigated the prevalence of PLs in a group of poststroke individuals. Fifty post-stroke individuals were examined with a structured interview/questionnaire to establish the presence of PLs; 27 of the patients (54\%) reported the presence of a PL. Two types of PL, postural and kinesthetic, were proposed. A postural PL, which involves the perception of a postural illusion, is a two-step process: the realization that the limb is not in the position currently perceived and the subsequent attenuation of the phantom when the actual position of the limb is accessed by another sensory modality, most often by vision. A kinesthetic PL is often perceived as a "real" movement or an improvement of the motor function. The spectrum of kinesthetic illusions ranges from simple to complex, and from involuntary to voluntary.

The SPL in this case seems to be different from the previously reported cases of postural and kinesthetic PLs. Staub et al. [9] reported the case of a female patient who showed intentional motor PL syndrome after infarction in the territory of the left anterior choroidal artery. Her illusion was induced by proximal movement of the paretic right limb or by a movement of the healthy arm or hand; however, in the latter case, it only occurred when the current task required the use of both hands. The intention to move the paretic limb was sufficient to trigger the illusion, whereas its passive movement had no effect. Khateb et al. [10] reported the case of a female patient who showed a left visual, tactile and intentional SPL caused by right subcortical hemorrhage. In this case, the illusion was most often experienced as a somesthetic phantom, but the SPL was rarely intentionally triggered or seen. Her SPL was not experienced permanently, it was only experienced when she decided to "trigger" it intentionally. The SPL was visually perceived whenever it was "triggered." She described it as "pale," "milk-white," and "transparent." In the case of Staub et al. [9], the SPL was induced by intentional movement of the paralyzed limb, whereas the case of Khateb et al. [10] differed in that the SPL could be intentionally moved.

Our case was similar to the case of Staub et al. [9] in that the SPL phenomenon was induced by the intention to move the paretic limb. In their case, the intention to move the paretic limb was sufficient to trigger the illusion, whereas in our case the intention to move the paralyzed arm at the same time as the trainer's facilitation operation was necessary to trigger the illusion.

\section{Pathogenesis of SPL in Stroke Patients}

The pathogenesis of PL phenomena still remains to be elucidated. Theories about its origins can be dichotomized according to whether they focus more on peripheral or central processes; however, the mechanisms underlying these phenomena remain elusive [12]. The mechanism underlying the appearance of SPLs in stroke patients has not been definitively explained; however, many previous reports have suggested a relationship to deep sensory

\section{Karger'=}




\section{Case Reports in Neurology}

Case Rep Neurol 2021;13:251-258

DOI: $10.1159 / 000513302$

Yamada et al.: Phantom Limb

deficits. Severe sensory and proprioceptive loss provokes the innate "neuromatrix" of the body image into constructing a phantom [1].

Our patient also presented severe deep sensory deficits, suggesting that the SPL may have been related to the divergence between the sensory input impairment and the body image, consistent with previous reports. In contrast, supratentorial cortex, basal ganglion and thalamus lesions are considered to be the lesions that are most commonly responsible for SPLs, and they are often associated with anosognosia for severe hemiplegia and with hemineglect [13].

However, in the present case, the SPL was not associated with anosognosia.

\section{Relationship between the Intention to Move the Paralyzed Arm and the SPL}

During voluntary movement, large numbers of neurons in the forebrain become active. The basal ganglia are neural structures within the motor and cognitive control circuits in the mammalian forebrain [14]. Staub et al. [9] investigated the clinical and anatomical correlates in a case of intentional motor PL syndrome using fMRI. The interruption of thalamic afferents, in which the responsible lesion destroyed the posterior part of the posterior limb of the internal capsule, damaging the corticospinal and thalamocortical tracts, may be responsible for the persistence and stability of the phantom by preventing any correction of the mismatch between expected and effective movement. The increased blood oxygen level-dependent signal in the basal ganglia-thalamus-cortex pathway during movement of the supernumerary hand may indicate that an abnormal closed-loop function of the thalamocortical system underlies the phantom phenomenon. A preserved sense of agency provided by an intact premotor process translating intention into action may lead to the vivid feeling of movement in a paralyzed limb.

In the present case, severely affected lesions were observed in the basal ganglia, internal capsule, and part of the thalamus (the lateral posterior nucleus, ventral anterior nucleus, ventral lateral nucleus, ventral posterior lateral nucleus, and ventral posterior medial nucleus). In contrast, the premotor cortex and supplementary motor cortex were not involved.

Kawahira's facilitation technique for paralytic limbs has been used for many years in poststroke paralysis at our hospital [15]. The hypothesized mechanism of action of facilitation in the hemiplegic upper limb and fingers is that the patient can realize his/her intended movements when neurons related to the intended movements are activated by the stretch reflex and neuronal excitation of the patient's intention comes from the prefrontal/premotor cortex. To facilitate extension of the isolated finger, it was quickly flexed by the therapist; the metacarpophalangeal joint was flexed by the therapist after saying the instruction "extend," and slight resistance against finger extension was applied during extension of the finger. These manipulations of the stretch reflex and light touch (resistance) maintain the $\alpha-\gamma$ linkage.

In the present case, no specific examination was conducted regarding the pathogenic mechanism underlying the SPL. However, despite the severe motor and sensory impairment, the afferent pathway from the muscles, that is, the proprioceptive pathway from the muscles and the somatosensory pathway by light touch to the premotor cortex, may be partially preserved, and neurons related to the intended movements in the premotor cortex are activated by the stretch reflex and neuronal excitation of the patient's intention comes. This fact may be related to induction of the SPL. We considered the mechanism underlying the SPL in this case to be similar to that reported by Staub et al. [9].

\section{Karger'=}




\section{Case Reports in Neurology}

\begin{tabular}{l|l}
\hline Case Rep Neurol 2021;13:251-258 \\
\hline DOI: 10.1159/000513302 & $\begin{array}{l}\text { @ 2021 The Author(s). Published by S. Karger AG, Basel } \\
\text { www.karger.com/crn }\end{array}$ \\
\hline
\end{tabular}

Yamada et al.: Phantom Limb

\section{Statement of Ethics}

This study was carried out in accordance with the recommendations of the Ethics Committee of the Nagasaki Kita Hospital. Written informed consent was obtained from the patient for the publication of this case report and any accompanying images.

\section{Conflict of Interest Statement}

The authors declare no conflict of interest in association with the present study.

\section{Funding Sources}

No funding was received for this study.

\section{Author Contributions}

M. Yamada and Y. Sasahara are occupational therapists, and they were involved in observation of the SPL and rehabilitation treatment. M. Seto and A. Satoh were involved as attending physicians. M. Tsujihata contributed to the preparation of the manuscript. All authors were equally involved in the medical management of the patient and approved the final version of the manuscript.

\section{References}

1 Melzack R. Phantom limbs and the concept of a neuromatrix. Trends Neurosci. 1990 Mar;13(3):88-92.

2 Cutting J. Body image disturbances in neuropsychiatry. In: Reynolds E, Trimble M, editors. The bridge between neurology and psychiatry. Edinburgh: Churchill Livingstone; 1989.

3 Critchley M. The parietal lobes. New York: Hafner; 1953.

4 Fredericks J. Phantom limb and phantom limb pain. In: Fredericks J, editor. Handbook of clinical neurology. Vol. 1 (45), Clinical neuropsychology. Amsterdam: Elsevier; 1985.

5 Riddoch G. Phantom limbs and body shape. Brain. 1941;64(4):197-222.

6 Halligan PW, Marshall JC, Wade DT. Three arms: a case study of supernumerary phantom limb after right hemisphere stroke. J Neurol Neurosurg Psychiatry. 1993 Feb;56(2):159-66.

7 Mazzoni M, Lucchin C, Meucci G, Vista M, Moretti P, Sartucci F. Supernumerary phantom limb after ischaemic stroke. Neurocase. 1997;3(3):223-30.

8 Miyazawa N, Hayashi M, Komiya K, Akiyama I. Supernumerary phantom limbs associated with left hemispheric stroke: case report and review of the literature. Neurosurgery. 2004 Jan;54(1):228-31.

9 Staub F, Bogousslavsky J, Maeder P, Maeder-Ingvar M, Fornari E, Ghika J, et al. Intentional motor phantom limb syndrome. Neurology. 2006 Dec;67(12):2140-6.

10 Khateb A, Simon SR, Dieguez S, Lazeyras F, Momjian-Mayor I, Blanke O, et al. Seeing the phantom: a functional magnetic resonance imaging study of a supernumerary phantom limb. Ann Neurol. 2009 Jun;65(6):698-705.

11 Antoniello D, Kluger BM, Sahlein DH, Heilman KM. Phantom limb after stroke: an underreported phenomenon. Cortex. 2010 Oct;46(9):1114-22.

12 Cipriani G, Picchi L, Vedovello M, Nuti A, Fiorino MD. The phantom and the supernumerary phantom limb: historical review and new case. Neurosci Bull. 2011 Dec;27(6):359-65.

13 Weinstein EA, Kahn RL, Malitz S, Rozanski J. Delusional reduplication of parts of the body. Brain. 1954;77(1):45-60.

\section{Karger'=}




\section{Case Reports in Neurology}

\begin{tabular}{l|l}
\hline Case Rep Neurol 2021;13:251-258 \\
\hline DOI: 10.1159/000513302 & $\begin{array}{l}\text { C } 2021 \text { The Author(s). Published by S. Karger AG, Basel } \\
\text { www.karger.com/crn }\end{array}$ \\
\hline Yamada et al. Phantom Limb
\end{tabular}

14 Graybiel AM, Aosaki T, Flaherty AW, Kimura M. The basal ganglia and adaptive motor control. Science. 1994;265(5180):1826-31.

15 Kawahira K, Shimodozono M, Etoh S, Kamada K, Noma T, Tanaka N. Effects of intensive repetition of a new facilitation technique on motor functional recovery of the hemiplegic upper limb and hand. Brain Inj. 2010;24(10):1202-13.
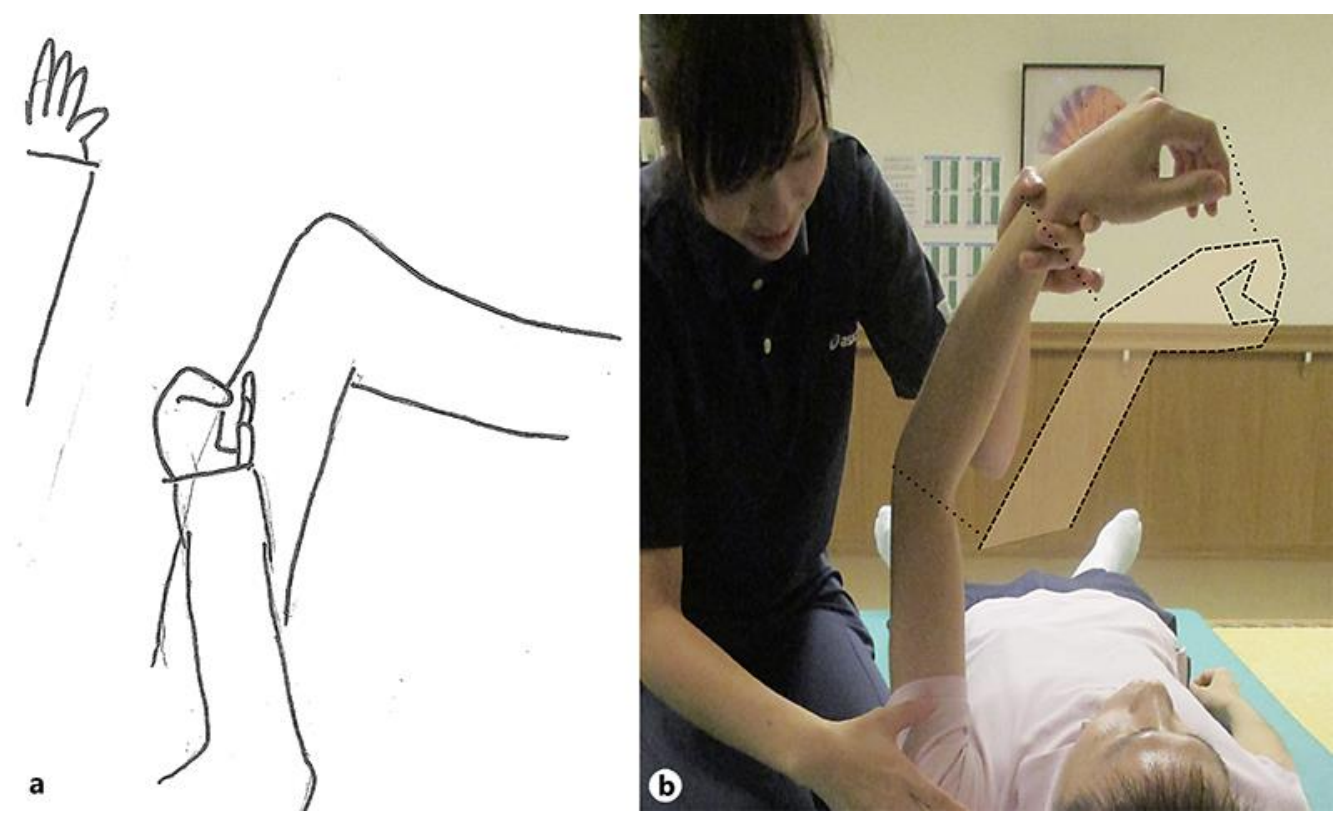

Fig. 1. a An illustration of the supernumerary motor phantom limb (SPL) drawn by the patient himself. b An illustration of the SPL drawn by the therapist according to the patient's statement. 


\section{Case Reports in Neurology}

\begin{tabular}{l|l}
\hline Case Rep Neurol 2021;13:251-258 \\
\hline DOI: 10.1159/000513302 & $\begin{array}{l}\text { C 2 2021 The Author(s). Published by S. Karger AG, Basel } \\
\text { www.karger.com/crn }\end{array}$ \\
\hline
\end{tabular}

Yamada et al.: Phantom Limb

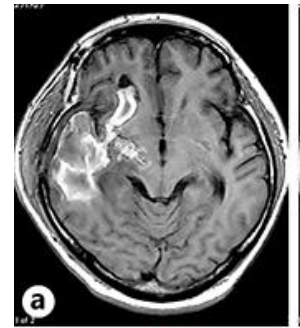

(2)

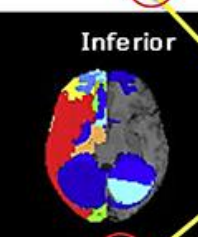

$\mathbf{R}$

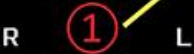
Superior

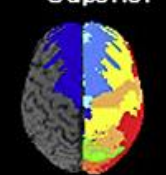

L

$\mathbf{R}$
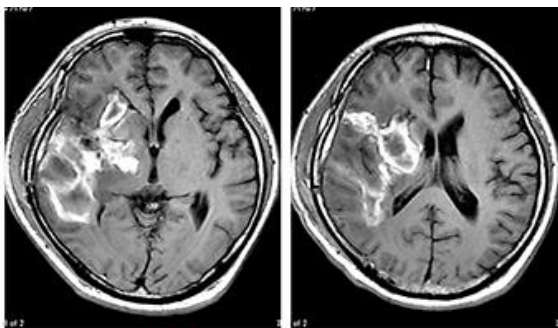

(3)

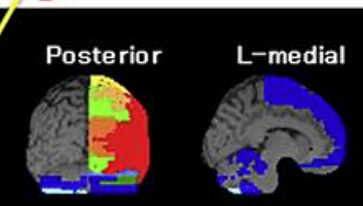

L

$\mathbf{R}$

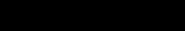

L-lateral
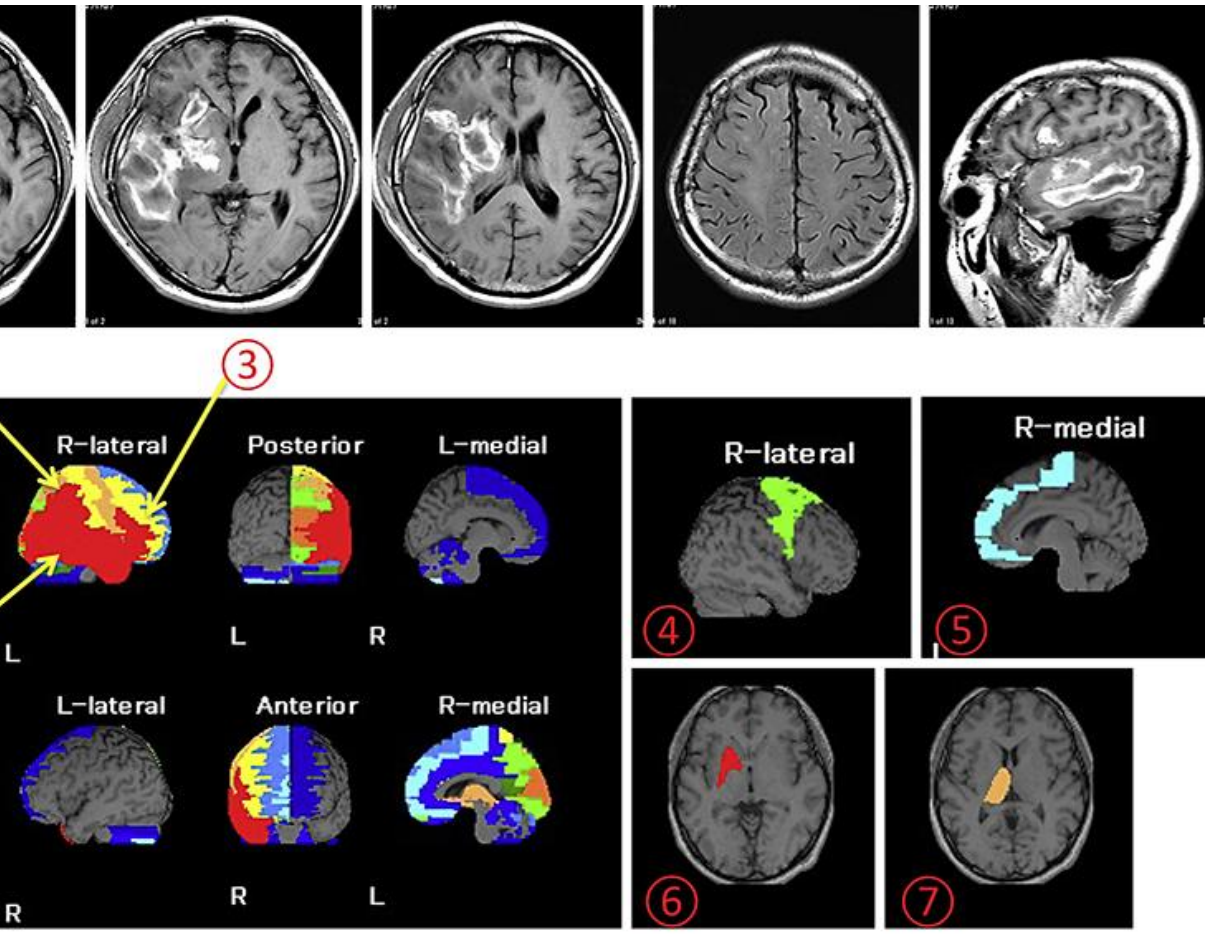

b

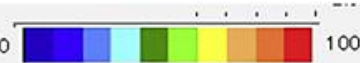

Fig. 2. a Fluid-attenuated inversion recovery MR images. The lesions were observed in the right temporal lobe subcortex, subfrontal cortex, putamen, internal capsule, and thalamus. b Single-photon emission computed tomography images were analyzed using the voxel-based stereotaxic extraction estimation software program. Hypoperfusion is displayed as extent $\%$ : (1) superior, middle and inferior temporal gyrus, 96\%; (2) inferior parietal lobule, 97.9\%; (3) inferior frontal gyrus, 95.9\%; (4) Brodmann area 6, 55.7\%; 5 medial frontal gyrus, 61.8\%; (6) lenticular nucleus, 97.4\%; and (7) thalamus, 70.3\%. 